\title{
Atividade antibacteriana in vitro de quatro espécies vegetais em diferentes graduações alcoólicas
}

MIRANDA, G.S.; SANTANA, G.S.; MACHADO B.B.; COELHO, F.P.; CARVALHO, C.A.*

União de Ensino Superior de Viçosa - UNIVIÇOSA, Departamento de Farmácia - FARMAPET, Av. Maria de Paula Santana, 740, Bairro Silvestre, 36570-000, Viçosa/MG-Brasil. *camiloamaro@yahoo.com.br

\begin{abstract}
RESUMO: Neste trabalho foi realizada a caracterização fitoquímica e avaliada a atividade antibacteriana in vitro dos extratos de Ageratum conyzoides L. (mentrasto), Gossypium hirsutum (algodão), Phyllanthus tenellus (quebra pedra), e Polygonum hydropiperoides (erva de bicho) frente à Staphylococcus aureus e Escherichia coli. Para a avaliação da atividade antibacteriana foi utilizado o método de difusão em ágar. Os testes foram realizados com o extrato nas graduações alcoólicas de 0 a $100 \%$ (v/v), na proporção de $20 \%$ (m/v - massa/extrator). Os testes fitoquímicos constataram a presença de açucares redutores, compostos fenólicos, flavonoides, taninos, triterpenos, e esteróides nas quatro espécies. O crescimento das culturas de $S$. aureus foi inibido por todos os extratos, com exceção do extrato de Mentrasto. A maior atividade de inibição foi observada pelo extrato de quebra pedra. Entretanto, nenhum dos extratos foi capaz de inibir o crescimento das cepas de E. coli. Os resultados são promissores, visto que três das quatro plantas selecionadas demonstraram possuir substâncias antibacterianas, o que motiva estudos subsequentes para o isolamento e identificação dos princípios ativos responsáveis por essa atividade, com potencial de uso na indústria farmacêutica.
\end{abstract}

Palavras-chave: Fitoterapia, Escherichia coli, Staphylococcus aureus

\begin{abstract}
In vitro antibacterial activity of four plant species at different alcoholic contents. In this study, phytochemical characterization was conducted and the in vitro antibacterial activity of extracts of Ageratum conyzoides L. (whiteweed), Gossypium hirsutum (cotton), Phyllanthus tenellus (shatterstone) and Polygonum hydropiperoides (swamp smartweed) was evaluated against Staphylococcus aureus and Escherichia coli. To assess the antibacterial activity, the agar diffusion method was used. Tests were performed with the extract at alcoholic contents from 0 to $100 \%(\mathrm{v} / \mathrm{v})$, at $20 \%$ proportion $(\mathrm{m} / \mathrm{v}$ - mass/extractor). Phytochemical tests indicated the presence of reducing sugars, phenolic compounds, flavonoids, tannins, triterpenes and steroids in all four species. The growth of $S$. aureus cultures was inhibited by all extracts, except for whiteweed extract. The highest inhibitory activity was observed for shatterstone. However, none of the extracts was capable of inhibiting the growth of $E$. coli strains. Results are promising since three of the four selected plants showed to have antibacterial substances, which stimulates further studies for the isolation and the identification of active principles responsible for this activity, with potential to be used in the pharmaceutical industry.
\end{abstract}

Key words: Phytotherapy, Escherichia coli, Staphylococcus aureus

\section{INTRODUÇÃO}

A espécie vegetal Agerantum conyzoides L. pertence à família Compositae (Asteraceae) é conhecida popularmente como mentrasto, nos levantamentos etnofarmacológicos são atribuídas a esta planta propriedade hemostática e cicatrizante (Lorenzi \& Matos, 2002). Conforme Momesso et al. (2009) a planta exerce elevada gama de atividade biológica, tais como: antimicrobiana, cicatrizante, no tratamento de queimaduras, tratamento de cólicas, diarréia, flatulência, reumatismo agudo, além de ação vasoconstritora, analgésica e anti-inflamatória.

De acordo com Lorenzi \& Matos (2002) o nome popular quebra pedra é usado para designar várias espécies do gênero Phyllanthus. Pertencente a família Euphorbiaceae a semelhança existente entre as espécies de Phyllanthus niruri L. e 
Phyllanthus tenellus Roxb dificulta sua identificação podendo explicar em parte o uso de ambas na medicina popular para os mesmos fins. Essas plantas têm sido empregadas popularmente para o tratamento de cálculos renais e urinários, infecções intestinais e urinárias, diabetes e hepatite (Gárcia et al. 2004).

Gossypium hirsutum L. conhecida como algodão pertence à família Malvaceae é cultivada principalmente para fornecimento de matéria prima para fins industriais. No Brasil a literatura etnofarmacológica refere seu uso na forma de chá, preparado com as folhas no tratamento de disenteria, hemorragia uterina e também, o emprego local das folhas como cicatrizante (Lorenzi \& Matos, 2002).

Conforme Cardoso et al. (2006) a espécie vegetal Polygonum hydropiperoides Michx conhecida popularmente como erva de bicho, é pertencente a família Polygonaceae. Muitas pessoas utilizam o chá dessa planta por via oral no tratamento de hemorroidas e por este motivo é importante conhecer mais detalhes sobre essa planta.

As doenças infecciosas ainda são uma das principais causas de morte no mundo, sendo de significativa importância o desenvolvimento de novos compostos antimicrobianos. Nesse contexto as plantas podem ser uma boa fonte para direcionar a busca por compostos promissores (Bertucci et al. 2009). Estas possuem várias vias metabólicas secundárias que dão origem a compostos como alcaloides, flavonoides, isoflavonoides, taninos, cumarinas, glicosídeos cardiotônicos, terpenos que por vezes, são específicos de determinadas famílias, gêneros ou espécies, e cujas funções, até pouco tempo, eram desconhecidas (Simões et al. 2004).

Considerando que a presença de substâncias antimicrobianas nos vegetais superiores não seja um fato recente, somente a partir da descoberta da penicilina é que a busca por novas moléculas alcançou maior impulso (Sartori, 2005 \& Silveira et al. 2009).

Embora as indústrias químicas e farmacêuticas tenham produzido uma imensa variedade de diferentes antibióticos nos últimos tempos, cada vez mais tem sido observado o aumento de microrganismos resistentes aos antimicrobianos disponíveis no mercado, o que incentiva a busca por novas fontes de substâncias, com atividades antimicrobianas (Ribeiro, 2008).

De acordo com Padilha et al. (2010) a resistência aos antimicrobianos é um problema sério em todo o mundo, sendo de fundamental importância a pesquisa por novos agentes antimicrobianos; nesse contexto, tem ocorrido um crescente interesse em avaliar a atividade antimicrobiana de plantas.
Neste trabalho, foi realizada a caracterização fitoquímica e avaliado a atividade antibacteriana in vitro dos fitoconstituintes presentes nos extratos em graduações alcoólicas crescentes de quatro espécies vegetais: Ageratum conyzoides L. (mentrasto), Gossypium hirsutum (algodão), Phyllanthus tenellus (quebra pedra) e Polygonum hydropiperoides (erva de bicho) frente à Staphylococcus aureus e Escherichia coli.

\section{METODOLOGIA}

\section{Obtenção e preparação do material vegetal}

As plantas algodão (Gossypium hirsutum L.); erva de bicho (Polygonum hydropiperoides Michx.); mentrasto (Ageratum conyzoides L.) e quebra pedra (Phyllanthus tenellus Roxb) foram coletadas em horta comunitária na cidade de Urucânia-MG, em fevereiro de 2010. Tais plantas foram identificadas conforme descrição de Lorenzi \& Matos (2002), sendo as exsicatas depositadas no Herbário da Universidade Federal de ViçosaMG (UFV), Brasil sob os números 34.240; 34.241; $34.242 ; 34.243$ respectivamente. Após a limpeza, foram secas por sete dias à temperatura ambiente ao abrigo da luz, seguidos de dois dias em estufa de circulação de ar forçado $\left(40 \pm 0,5^{\circ} \mathrm{C}\right)$ separadamente. $\mathrm{O}$ material vegetal seco (folhas, inflorescência e caule) foi então triturado em moinho de facas (Marconi ${ }^{\circledR}$ ) e armazenado separadamente ao abrigo da luz e umidade. Os experimentos foram realizados nos laboratórios da União de Ensino Superior de Viçosa-MG.

\section{Preparação dos extratos}

Os extratos aquosos e alcoólicos para a avaliação fitoquímica foram preparados a $10 \%$ $(\mathrm{m} / \mathrm{v})$ por agitação ultra sônica durante uma hora. Em seguida foram filtrados à vácuo, em papel de filtro com porosidade de $14 \mu \mathrm{m}$. Nos filtrados foram realizados as seguintes reações de caracterização fitoquímica: açúcares redutores (reação de Benedict: Fehling A e B), alcaloides (reação de Wagner, Dragendorff, e Mayer), compostos fenólicos (reação de precipitação com cloreto férrico), cumarinas (observação sob a luz ultravioleta), flavonoides (reação de Shinoda, observação sobre luz ultravioleta), heterosídeos cardiotônicos (reação com hidróxido de potássio/ácido pícrico e teste de Kedde), naftoquinona (reação ácido/ base), saponinas (reação com aldeídos aromáticos e teste de espuma), taninos (reação com acetato de Chumbo, reação de precipitação de proteínas), triterpenos e esteroides (reação com anidrido acético e ácido sulfúrico concentrado), segundo metodologia descrita em Simões et al. (2004). 
Para avaliação da atividade antibacteriana os extratos aquosos e etanólico, foram preparados nas seguintes graduações alcoólicas crescentes $(0 \mathrm{a}$ $100 \%$ - v/v) a $20 \%$ ( $\mathrm{m} / \mathrm{v}$ - massa volume de extrator). As soluções de álcool:água foram preparadas utilizando álcool etílico PA e água destilada de forma a obter as seguintes graduações 0 a $100 \%$ com intervalo de $10 \%$. Assim o extrato em graduação alcoólica $0 \%$ era constituído apenas por água destilada e o extrato de graduação alcoólica 100\% era constituído apenas por álcool.

Após $24 \mathrm{~h}$ o sobrenadante foi recolhido e centrifugado a $3.000 \mathrm{rpm}$, posteriormente foram retirados $2 \mathrm{~mL}$ do mesmo sendo este seco em estufa a $\left(40 \pm 0,5^{\circ} \mathrm{C}\right)$ por $24 \mathrm{~h}$ e em seguida ressuspendido (nas soluções de álcool:água correspondentes) de forma a obter as concentrações de $200 \mathrm{mg} / \mathrm{mL}$ e $500 \mathrm{mg} / \mathrm{mL}$ de cada extrato.

\section{Avaliação da atividade antimicrobiana}

Os microrganismos testados foram cepas de Staphylococcus aureus (ATCC 33591) e Escherichia coli (K12), fornecidas pelo laboratório de Imunovirologia Molecular da UFV. A avaliação da atividade antibacteriana das espécies foi realizada através do método de difusão (Kirby-Bauer) em meio de cultura Muller-Hinton (Anvisa, 2004), a partir de poços perfurados em ágar com três $\mathrm{mm}$ de diâmetro e profundidade.

Colônias das cepas de $S$. aureus e E. coli foram preparadas separadamente em ágar Muller-Hinton e diluídas em solução salina $(0,9 \%$ - 0,5 da escala de Mac-Farland) correspondendo a aproximadamente $2.10^{8} \mathrm{UFC} / \mathrm{mL}$ (Ribeiro, 2008). Foi realizado controle da absorbância das suspensões dos microrganismos incubados em espectrofotômetro $(600 \mathrm{~nm})$. Posteriormente, 500 $\mu \mathrm{L}$ da suspensão do microrganismo foi misturada ao meio Muller-Hinton a $37^{\circ} \mathrm{C}$, sendo em seguida vertido em placas estéreis. Os poços foram preparados após a solidificação do meio.

O experimento foi acompanhado de controles positivos (Ciprofloxacino a $0,1 \mathrm{mg} / \mathrm{mL}$ ) contra a bactéria $E$. coli e Amoxicilina a $0,1 \mathrm{mg} / \mathrm{mL}$ ) contra Staphylococcus aureus e controle negativo ( álcool etílico PA).

Foi realizado um teste a parte, para avaliar a atividade bactericida do álcool utilizado na preparação dos extratos, em que, cada poço recebeu $10 \mu \mathrm{L}$ de álcool etílico em diferentes graduações alcoólicas (0 a 100\% - v/v).

Os testes foram realizados com $10 \mu \mathrm{L}$ de cada extrato das respectivas plantas em suas respectivas graduações alcoólicas (0 a 100\% v/v) (Ribeiro, 2008). Após 24 horas, em estufa a $37^{\circ} \mathrm{C}$ (Anvisa, 2004) o diâmetro do halo de inibição foi mensurado. Os testes foram realizados em triplicata sendo considerado como resultado final de cada extrato a média das três medidas e como susceptível halo igual ou acima de oito $\mathrm{mm}$ de diâmetro de acordo com os critérios apresentados por Parekh \& Chanda (2007) e Santos et al. (2007).

\section{RESULTADOS E DISCUSSÃO}

Os testes fitoquímicos realizados em cada uma das quatro espécies vegetais: Ageratum conyzoides L. (mentrasto); Gossypium hirsutum (algodão); Phyllanthus tenellus (quebra pedra) e Polygonum hydropiperoides (erva de bicho), permitiram constatar a presença de açucares redutores, compostos fenólicos, flavonoides, taninos, triterpenos e esteroides, em todas as plantas analisadas (Tabela 1).

Conforme Leão (2007) as plantas sintetizam uma enorme variedade de metabolitos que são geralmente classificados em dois grupos de acordo com as suas funções. Os metabolitos primários que são essenciais ao crescimento e desenvolvimento da planta e os metabolitos secundários que são extremamente diversos e variáveis, desempenhando o papel de garantir a sobrevivência da planta em seu habitat natural.

Dentre as substâncias do metabolismo secundário relacionadas à defesa química, estão os alcaloides, saponinas, flavonoides entre outros (Machado, 2009).

A análise fitoquímica da planta algodão (Gossypium hirsutum L.) apresentou alcaloides, cumarinas, saponinas, além dos metabolitos citados (Tabela 1). Bouzada et al. (2009) ao estudarem a planta encontraram presentes triterpenos, saponinas, cumarinas, flavonoides e antraquinonas. Conforme Lorenzi \& Matos (2002) a análise fitoquímica dos botões florais desta planta registra a presença de óleo essencial, contendo compostos carbonílicos, hidrocarbonetos, álcoois e indol; registra também resinas, esteróis, triterpenos.

A análise fitoquímica da planta erva de bicho (Polygonum hydropiperoides M.) apresentou cumarinas e saponinas entre outros (Tabela 1). Lorenzi \& Matos (2002) relatam que na sua composição química, destaca-se a presença de flavonoides (pelargonidina, quercetina, luteolina, rutina, fitosterina); saponinas, taninos, ácidos orgânicos e óleo essencial. Em estudo realizado por Jácome et al. (2004) com Polygonum hydropiperoides coletada no outono e na primavera foi detectado a presença de esteroides e/ou triterpenos, cumarinas, flavonoides, polifenóis, taninos e saponinas.

Corroborando com os resultados encontrados, na análise fitoquímica de Polygonum hydropiperoides Cardoso et al. (2006) cita que as espécies de Polygonum apresentam grande 
TABELA 1. Triagem fitoquímica de extratos aquosos e etanólicos das espécies Gossypium hirsutum (algodão); Polygonum hydropiperoides (erva de bicho); Ageratum conyzoides L. (mentrasto) e Phyllanthus tenellus (quebra pedra).

\begin{tabular}{|c|c|c|c|c|c|c|c|c|}
\hline \multirow{3}{*}{ Classe de compostos } & \multicolumn{8}{|c|}{ Amostras } \\
\hline & \multicolumn{2}{|c|}{ Algodão } & \multicolumn{2}{|c|}{ Erva de Bicho } & \multicolumn{2}{|c|}{ Mentrasto } & \multicolumn{2}{|c|}{ Quebra Pedra } \\
\hline & Ext.aq. & Ext.et. & Ext.aq. & Ext.et. & Ext.aq. & Ext.et. & Ext.aq & Ext.et. \\
\hline Açucares redutores & $++^{*}$ & ++ & ++ & ++ & ++ & ++ & ++ & ++ \\
\hline Compostos Fenólicos & ++ & ++ & ++ & ++ & ++ & ++ & ++ & ++ \\
\hline Alcaloides & ++ & ++ & - & - & ++ & ++ & ++ & ++ \\
\hline Cumarinas & ++ & ++ & ++ & ++ & - & ++ & - & - \\
\hline Compostos Antracênicos & $-^{*}$ & - & - & - & - & - & - & - \\
\hline Flavonoides & ++ & ++ & ++ & ++ & ++ & ++ & ++ & ++ \\
\hline Heterosídeo Cardiotônicos & - & - & - & - & - & - & - & - \\
\hline Naftoquinonas & - & - & - & - & - & - & - & - \\
\hline Saponinas & ++ & ++ & ++ & ++ & ++ & ++ & - & - \\
\hline Taninos & ++ & ++ & ++ & ++ & ++ & ++ & ++ & ++ \\
\hline Triterpenos e Esteroides & - & ++ & - & ++ & - & ++ & - & ++ \\
\hline
\end{tabular}

Ext.aq. - extrato aquoso; Ext.et. - Extrato etanólico; (+) - Resultado positivo; (-) - Resultado negativo; * - Resultados em duplicata

diversidade de metabólitos secundários, sendo que algumas espécies são ricas em flavonoides, outras em terpenos.

A triagem fitoquímica da planta mentrasto (Ageratum conyzoides L.) apresentou alcaloides, cumarinas, saponinas entre outros (Tabela 1). De acordo com Lima et al. (2010) as folhas de Ageratum conyzoides contém óleos essenciais rico em betacariofileno e os precocenos I e II (tipo de terpeno). As sementes fornecem $14 \%$ de oléo fixo que contém ácidos graxos livres, mono, di, e triglicerídeos, ceras e hidrocarbonetos. Castro et al. (2004) destacam que entre os constituintes fixos encontrados nesta planta foram identificados esteróis, quercetina (flavonoide), campferol, glicosídios do campferol, ácidos caféico (composto fenólico), fumárico e várias flavonas polimetoxiladas. Lorenzi \& Matos (2002) relatam que foram também isolados os alcaloides pirrolizidínicos licopsamina e equinatina.

A análise fitoquímica da planta quebra pedra (Phyllanthus tenellus Roxb.) apresentou alcaloides, flavonoides entre outros (Tabela 1). Tal resultado também foi evidenciado por Calixto et al. (1997); Lorenzi \& Matos (2002); Júnior et al. (2005). Em estudo realizado por Nascimento et al. (2008) com três espécies de Phyllanthus (P. niruri, P. amarus e $P$. tenellus), foi encontrado a presença de antraquinonas, flavonoides, taninos e terpenoides, e ausência de antocianinas e cumarinas nas três espécies.

Os microrganismos utilizados (S. aureus e E. coli ) para a avaliação antibacteriana foram escolhidos por serem recomendados como padrões para testes de suscetibilidade antimicrobiana, sendo responsáveis por várias formas de infecções em humanos e adquirirem, com maior frequência, resistência aos antimicrobianos (Oplustil et al. 2000).

Das quatro plantas testadas apenas o algodão, quebra pedra e erva de bicho mostraram atividade frente à $S$. aureus nas concentrações de $200 \mathrm{mg} / \mathrm{mL}$ e de $500 \mathrm{mg} / \mathrm{mL}$. Não sendo observada qualquer atividade inibitória por parte do extrato da planta mentrasto nestas concentrações. Os resultados das respectivas médias dos diâmetros dos halos de inibição podem ser visualizados na Tabela 2.

Os resultados obtidos com o extrato na concentração de $200 \mathrm{mg} / \mathrm{mL}$ para as plantas algodão, quebra pedra e erva de bicho foram promissores em diferentes graduações alcoólicas, ou seja, apresentaram halos de inibição maior ou igual a oito $\mathrm{mm}$ de diâmetro, sendo estes mais expressivos na concentração de $500 \mathrm{mg} / \mathrm{mL}$.

$\mathrm{Na}$ Figura 1 podem ser observados os halos de inibição produzidos pelos extratos das plantas algodão; erva de bicho e quebra pedra, na concentração de $500 \mathrm{mg} / \mathrm{mL}$ e a ausência de halo de inibição do extrato da planta mentrasto frente a S. aureus.

Triterpenos e esteroides, taninos e flavonoides encontraram-se presentes nos extratos das espécies ativas contra $S$. aureus (Tabela 1). $A$ atividade antibacteriana observada para as espécies avaliadas pode estar relacionada com tais classes de compostos, que se mostraram ativos em diferentes estudos descritos na literatura (Duarte et 
TABELA 2. Diâmetros médios em $\mathrm{mm}$ dos halos de inibição frente a Staphylococcus aureus obtidos com os extratos das plantas em graduações alcoólicas crescentes.

\begin{tabular}{|c|c|c|c|c|c|c|c|c|}
\hline \multirow{2}{*}{$\begin{array}{c}\text { Graduações } \\
\text { alcoólicas } \\
\text { (\%) }\end{array}$} & \multicolumn{4}{|c|}{$200 \mathrm{mg} / \mathrm{mL}$} & \multicolumn{4}{|c|}{$500 \mathrm{mg} / \mathrm{mL}$} \\
\hline & Mentrasto & Algodão & $\begin{array}{c}\text { Erva de } \\
\text { bicho }\end{array}$ & $\begin{array}{l}\text { Quebra } \\
\text { Pedra }\end{array}$ & Mentrasto & Algodão & $\begin{array}{c}\text { Erva } \\
\text { de bicho }\end{array}$ & $\begin{array}{c}\text { Quebra } \\
\text { Pedra }\end{array}$ \\
\hline 0 & 0 & 0 & 0 & 0 & 0 & 0 & 0 & 0 \\
\hline 10 & 0 & 5 & 5 & 6 & 0 & 6 & 6 & 8 \\
\hline 20 & 0 & 6 & 6 & 7 & 0 & 7 & 8 & 9 \\
\hline 30 & 0 & 6 & 6 & 8 & 0 & 9 & 8 & 9 \\
\hline 40 & 0 & 7 & 7 & 8 & 0 & 9 & 8 & 10 \\
\hline 50 & 0 & 8 & 7 & 9 & 0 & 8 & 9 & 10 \\
\hline 60 & 0 & 8 & 8 & 10 & 0 & 9 & 10 & 12 \\
\hline 70 & 0 & 8 & 7 & 10 & 0 & 10 & 8 & 11 \\
\hline 80 & 0 & 7 & 7 & 8 & 0 & 9 & 7 & 10 \\
\hline 90 & 0 & 7 & 7 & 7 & 0 & 8 & 9 & 10 \\
\hline 100 & 0 & 6 & 8 & 9 & 0 & 10 & 10 & 12 \\
\hline$C+$ & 18 & 18 & 18 & 18 & 18 & 18 & 18 & 18 \\
\hline C - & 0 & 0 & 0 & 0 & 0 & 0 & 0 & 0 \\
\hline
\end{tabular}

(C+) Controle positivo (Amoxicilina); (C-) Controle negativo (Álcool PA)

al. 2002).

$\mathrm{Na}$ verificação preliminar da atividade antibacteriana da planta Gossypium hirsutum (algodão), foi observado atividade inibitória frente a $S$. aureus sendo que, os resultados foram promissores a partir da graduação alcoólica de $30 \%$ (Figura 1A).

De acordo com Macedo et al. (2007) algumas plantas possuem compostos ou substâncias que podem afetar, o desenvolvimento e a reprodução dos insetos, provocando antibiose, por isso são denominados antibióticos. Ainda de acordo com este autor na planta algodão há uma série de aldeídos-terpenos, como o gossipol, heliocidas e hemigossipolone, que conferem resistência a esta planta ao ataque de pragas.

$\mathrm{Na}$ pesquisa preliminar da atividade antibacteriana da planta Polygonum hydropiperoides (erva de Bicho), foi observado atividade contra $S$. aureus (Figura 1B). Verificou-se que a planta apresentou atividade antibacteriana, praticamente em todas as graduações alcoólicas, com exceção apenas do extrato a $0 \%$. Observa-se também que a atividade antibacteriana produziu halos maiores na graduação alcoólica de 60 e 100\%.

Bussmann et al. (2010) ao pesquisarem propriedades antibacterianas em 141 espécies vegetais contra Escherichia coli, Staphylococcus aureus dentre outras, verificaram que os extratos etanólicos apresentaram maior atividade e um espectro muito mais amplo de ação em relação aos extratos aquosos.

Lorenzi \& Matos (2002) relatam que esta planta possui óleo essencial que contém o poligodial, um diálcool sesquiterpênico tóxico para fungos e dotado de propriedades anti-inflamatória e analgésica, compatível com as ações preconizadas para esta planta pela medicina popular.

Os terpenos são chamados de inseticidas naturais e esta classe integra os limonóides, limoneno e o mirceno, os quais desempenham um papel de proteção às plantas contra os insetos. Os terpenos são formados por unidades básicas de pirofosfato de isopentenila ou isopreno ativo, originando os triterpenos e os sesquiterpenos já citados na literatura como substâncias dotadas de ação bactericida (Arantes et al. 2005). Conforme Sartori (2005) tem sido demonstrado que os terpenos são ativos contra diversos microrganismos. Seu mecanismo de ação provável envolve a ruptura da membrana celular por compostos lipofílicos.

No estudo da atividade antimicrobiana da planta Phyllanthus tenellus (quebra Pedra), foi observada atividade contra $S$. aureus. A razão pela qual a graduação alcoólica de $0 \%$ não apresentou halo de inibição (Figura 1C) pode ser atribuída a uma menor polaridade do(s) composto(s) ativo(s) o que provavelmente tenha impedido a sua extração.

Entre as três espécies vegetais analisadas que demonstraram atividade frente a $S$. aureus; Phyllanthus tenellus (quebra Pedra), foi a que produziu halos maiores. Por meio dos resultados, 

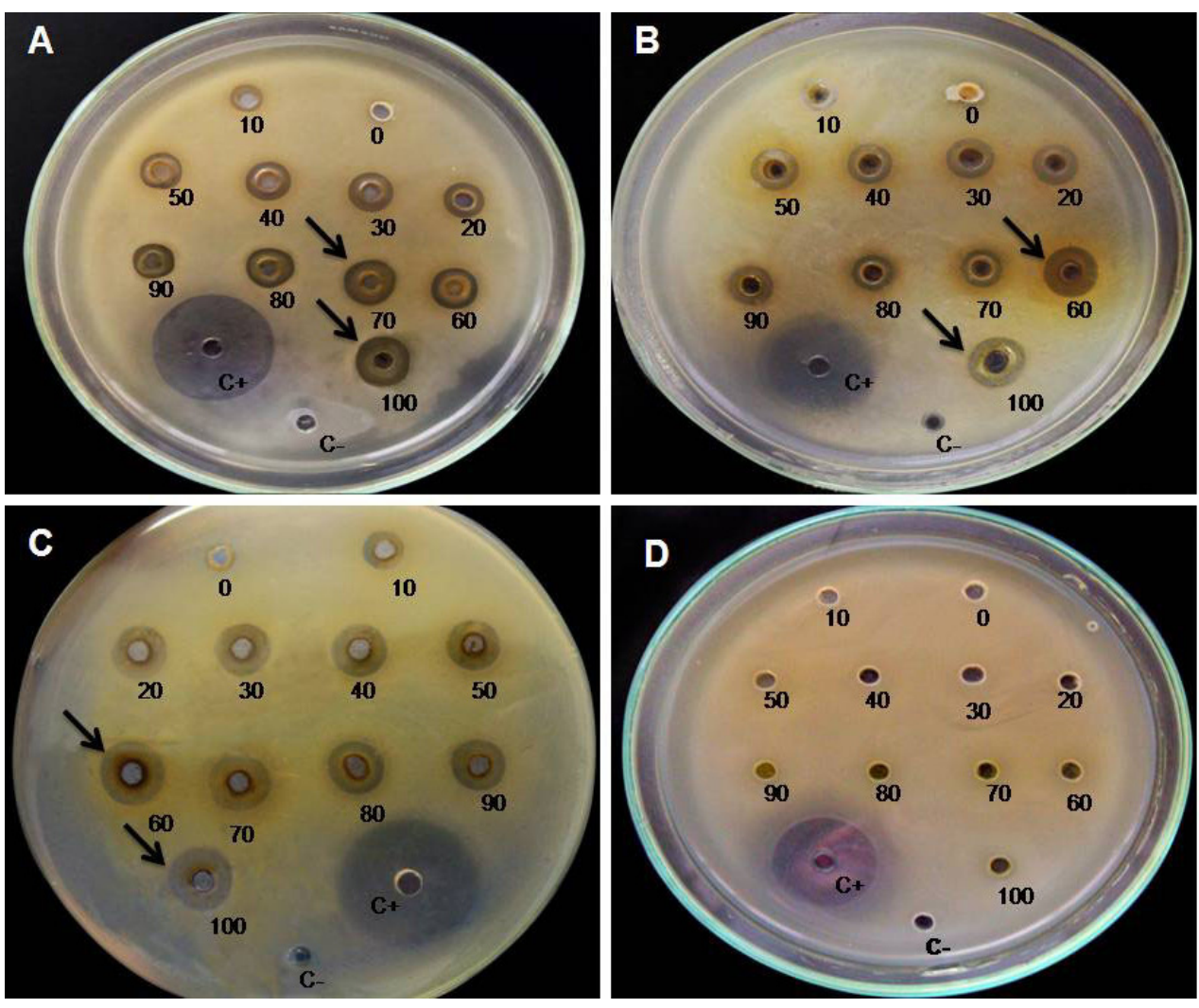

FIGURA 1. Atividade antibacteriana dos extratos em diferentes graduações alcoólicas na concentração de 500 $\mathrm{mg} / \mathrm{mL}$ frente a S. aureus. (A) Algodão (Gossypium hirsutum); (B) Erva de bicho (Polygonum hydropiperoides), (C) Quebra pedra (Phyllanthus tenellus) e (D) Mentrasto (Ageratum conyzoides L.). (A, B, D) - Vista superior da placa; (C) - Vista inferior da placa. (C+) Controle positivo (Amoxicilina); (C-) Controle negativo (Álcool PA).

foi possível verificar que os extratos das plantas nas graduações alcoólicas de 60, 70 e 100\%, apresentaram resultados mais expressivos.

Oliveira et al. (2007) ao realizarem um rastreamento com 26 plantas do sudeste brasileiro, verificaram que os melhores resultados foram obtidos com as plantas Lantana lilacina e Phyllanthus tenellus, uma vez que estas apresentaram boa atividade bactericida após passarem por um processo de microdiluição.

$\mathrm{Na}$ pesquisa de atividade antimicrobiana da planta Ageratum conyzoides (mentrasto), não foi observada qualquer atividade inibitória por parte do seu extrato (Figura 1D). Corroborando com esses resultados Chah et al. (2006) ao avaliar extratos metánolicos de Agerantum conyzoides dentre outras plantas frente a bactérias isoladas de feridas (Staphylococcus aureus, E. coli, Pseudomonas aeruginosa, Proteus spp., Shigella spp.) não observaram qualquer atividade antimicrobiana por parte desta planta.

Com relação à atividade frente à bactéria E. coli (K12) nenhuma das plantas em estudo apresentou atividade inibitória; sendo observado apenas o halo de inibição do controle positivo com o antibiótico Ciprofloxacino $(0,1 \mathrm{mg} / \mathrm{mL})$.
Conforme Sartori (2005) a parede celular bacteriana dos Gram positivos é menos complexa e apresenta maior permeabilidade quando comparada as Gram negativas. Tal resultado pode ser explicado porque a membrana externa das bactérias Gram negativas apresenta-se como uma barreira a penetração de numerosas moléculas de antibióticos, e, além disso, o espaço periplasmático contém enzimas capazes de quebrar moléculas estranhas (Tortora et al. 2005).

No estudo de Bussmann et al. (2010) com 141 espécies vegetais verificaram que os extratos etanólicos de 51 espécies inibiu o crescimento da bactéria Escherichia coli e 114 extratos etanólicos inibiu o crescimento da bactéria Staphylococcus aureus, o que demonstrou uma maior atividade sobre as bactérias Gram positivas.

De acordo com Vidal et al. (1998) e Espinosa et al. (2003) a bactéria E. coli (K12) é comumente utilizada em muitos institutos e centros de pesquisa de biotecnologia para investigação molecular, tendo sido observado alta capacidade desta bactéria apresentar mutações o que a torna resistente aos agentes antimicrobianos.

Silveira et al. (2009) relatam que o método de poços se baseia na difusão radial das substâncias 
e é o mais adequado para testar a difusão de substâncias em extratos etanólicos de plantas; no entanto algumas substâncias com solubilidade e difusibilidade distintas apresentam diferentes capacidades de difusão e dissociação em ágar. O teste de difusão em ágar tem eficiência para substâncias que são solúveis em água, possibilitando difusão destas através do meio de cultura (Silveira et al. 2009). Além disso, vários fatores como a presença de enzimas bacterianas, a composição do meio, a difusão da substância no meio, a densidade do inoculo, o período de incubação, a temperatura a estabilidade da substância em uso e a massa molecular, podem dificultar a difusão no meio de cultura (Ribeiro \& Soares, 2000).

Com relação ao teste realizado a fim de verificar a atividade bactericida do álcool utilizado para a preparação dos extratos, nas diferentes graduações alcoólicas ( 0 a $100 \%$ - v/v), todos os resultados foram negativos. Assim ficou evidenciado que a função do álcool era apenas de possibilitar a extração e veiculação do(s) composto(s) dotado(s) de atividade antibacteriana. Tal resultado atribuise ao fato do álcool volatilizar rapidamente, o que possibilitou o crescimento dos microrganismos.

$O$ estudo de vegetais permite detectar frações bioativas ou substâncias com atividade antimicrobiana. Nesse sentido, grande número de plantas tem sido investigado no seu potencial farmacológico, e o estudo da atividade antimicrobiana constitui de grande importância devido ao crescente problema de resistência de bactérias aos antimicrobianos em uso na terapêutica (Silveira et al. 2009).

Dentre os resultados obtidos na prospecção fitoquímica os compostos fenólicos, sendo que os flavonoides e taninos também encontramse classificados nesta classe majoritária, foram verificados como positivos em todos os extratos analisados. De acordo com Arantes et al. (2005) os flavonoides constituem um grande grupo de pigmentos vegetais de ampla distribuição na natureza que protegem as plantas contra infecções bacterianas e fúngicas. Silva et al. (2009) citam que compostos fenólicos podem apresentar atividade antibacteriana.

Essa atividade pode ser justificada pela habilidade dos flavonoides em formar complexos com proteínas solúveis extracelulares e com a parede celular, ou ainda o caráter lipofílico de alguns flavonoides ser responsável pela ruptura da membrana celular dos microrganismos (Sartori, 2005). No entanto, tal evidência deve ser objeto de novas pesquisas que possam verificar se a atividade das plantas depende de um único princípio ativo ou do conjunto de várias substâncias, podendo ser justificado uma ação sinérgica entre os metabólitos encontrados.

\section{CONCLUSÃO}

Os testes fitoquímicos realizados em cada uma das espécies vegetais nos permitiram constatar a presença de metabolitos secundários que podem estar relacionados com a atividade antibacteriana frente à Staphylococus aureus. Entretanto nenhum dos extratos analisados foi capaz de inibir o crescimento da bactéria Escherichia coli (K12). As espécies analisadas constituem uma fonte potencial para produção de agentes antibacterianos frente a Staphylococus aureus, exceto a espécie mentrasto (Ageratum conyzoides) pois esta não mostrou qualquer atividade antibacteriana nas concentrações analisadas.

O Brasil é o país de grande biodiversidade, no entanto as pesquisas aqui realizadas são insuficientes, tendo em vista que grande parte das moléculas que consumimos são importadas. Nesse contexto é importante que parcerias entre a indústria farmacêutica brasileira e as universidades possam ser realizadas com ênfase na busca por novas substâncias, que são nossas por direito. Dessa forma, os resultados desse trabalho motivam estudos posteriores a fim de isolar e identificar os princípios ativos responsáveis por tal atividade passíveis ou não de utilização na indústria farmacêutica.

\section{AGRADECIMENTOS}

Agradecemos à União de Ensino Superior de Viçosa - UNIVIÇOSA e a Universidade Federal de Viçosa - UFV, pelo apoio concedido nos experimentos.

\section{REFERÊNCIA}

ALIGIANIS, N. et al. Composition and antimicrobial activity of the essential oil of two Origanum species. Journal of Agricultural and Food Chemistry, Washington, v.49, p.4168-4170. 2001.

ANVISA, Agência Nacional de Vigilância Sanitária. Manual de Microbiologia Clínica para o Controle de Infecção em Serviços de Saúde. (2004) Módulo IV Descrição dos Meios de Cultura Empregados nos Exames Microbiológicos. SEPN 515, Edifício Omega. Bloco B, Brasília (DF), CEP 70770-502 1. Ed. 2004.

ARANTES, V.P. et al. Plantas do cerrado brasileiro com atividade contra Mycobacterium fortuitum. Revista de Ciências Farmacêuticas Básica e Aplicada, Araraquara, v.26, n.3, p.195-198, 2005.

BERTUCCI, R.A. et al. Initial antimicrobial activity studies of plants of the riverside forests of the southern Uruguay.

Revista Brasileira de Farmacognosia, São Paulo, v.19 n.1, p.20-25, jan./mar. 2009.

BOUZADA, M.L.M. et al. Busca de novas drogas antimicrobianas a partir de vegetais. Principia, Universidade Federal de Juiz de Fora, Juiz de Fora, MG, Brasil 2009. Disponível em: http://www.ufjf.br/principia/ files/2009/09/071.pdf. Acesso em 18/09/2010.

Rev. Bras. PI. Med., Botucatu, v.15, n.1, p.104-111, 2013. 
BUSSMANN, R.W. et al. Minimum inhibitory concentrations of medicinal plants used in Northern Peru as antibacterial remedies. Journal of Ethnopharmacology, v.132, p.101-108, 2010.

CALIXTO, J.B. et al. The plants of the genus Phyllanthus as apotential source of new drugs. Ciência e Cultura, São Paulo, v.49, n.5/6, p.422-432, 1997.

CARDOSO, C.A.L.; HONDA, N.K.; DIAS, E.S. Avaliação do perfil cromatográfico em espécies de Polygonum e amostras comercializadas como "erva-de-bicho" Revista Brasileira de Farmacognosia, São Paulo, v.16 n.2, p.236-245, abr./jun. 2006.

CASTRO, H.G. et al. Teor e Composição do Óleo essencial de cinco acessos de Mentrasto. Química Nova, São Paulo, v.27, n.1, p.55-57, 2004.

$\mathrm{CHAH}, \mathrm{K} . \mathrm{F}$. et al. Antibacterial and wound healing properties of methanolic extracts of some Nigerian medicinal plants. Journal of Ethnopharmacology, v.104, p.164-167, 2006.

DUARTE, M.G.R. et al. Perfil fitoquímico e atividade antibacteriana in vitro de plantas invasoras. Revista Lecta, Bragança Paulista-SP, v.20, n.2, p.177-182, jul./ dez. 2002.

ESPINOSA, A.E.S. et al. Verificación rápida de la pureza microbiológica de bancos de Escherichia coli K12. Biotecnología Aplicada, Cuba, v.20, n.4, 2003.

GARCIA, C.M. et al. Estudo Morfo-Anatômico de Phyllanthus niruri L. e Phyllanthus tenellus Roxb. Acta Farmacêutica Bonaerense, Buenos Aires, v.23, n.1, p.67-70, 2004.

HOLETZ, F.B. et al. Screening of some plants used in the Brazilian folk medicine for the treatment of infectious diseases. Memórias do Instituo Oswaldo Cruz, v.97, n.7, p.1027-1031, 2002.

JÁCOME, R.L.R.P. et al. Caracterização farmacognóstica de Polygonum hydropiperoides Michaux e P. spectabile (Mart.) (Polygonaceae). Revista Brasileira de Farmacognosia, São Paulo, v.14, n.1, jan./jun. 2004.

JÚNIOR, A.A.A. et al. Folhas de Chá: Plantas Medicinais na Terapêutica Humana. Viçosa-MG: Ed. UFV, 2005. 233p. LEÃO, J.D.J. Bioatividade de extratos vegetais no controle de Sitophilus oryzae (Linné, 1973) em arroz. 2007, 91p. Tese (Doutorado) apresentada ao Programa de Pósgraduação em Agronomia. Área de concentração em produção vegetal da Universidade Federal de Santa Maria (UFSM, RS) - Santa Maria, RS, Brasil.

LIMA, R.K. et al. Caracterização química e atividade inseticida do óleo essencial de Ageratum conyzoides L. sobre a lagarta-do-cartucho do milho Spodoptera frugiperda (Smith, 1797) (Lepidoptera: Noctuidae). Bioscience journal, Uberlândia, v.26, n.1, p.1-5, jan./ feb., 2010.

LORENZI, H. e MATOS, F.J.A. Plantas Medicinais no Brasil: nativas e exóticas. Nova Odessa, São Paulo: Instituto Plantarum, 2002. 512p.

MACEDO, L.P.M.; UEMERSON, S.C.; VENDRAMIM, J.D. Gossipol: Fator de resistência a insetos-praga. Campo digital, Campo Mourão, v.2, n.1, p.34-42, 2007.

MACHADO, R.C.M. Interação inseto-planta e suas implicações no manejo integrado de pragas. 2009, 58p. (Monografia) Curso de Pós-graduação Lato Sensu da
Universidade Federal do Rio Grande do Sul, Porto Alegre, RS, Brasil.

MOMESSO, L.S. et al. Atividade antitumoral do Ageratum conyzoides L. (Asteraceae). Revista Brasileira de Farmacognosia, São Paulo, v.19, n.3, p.660-663, jul./ set. 2009.

NASCIMENTO, J.E. et al. Estudo fitoquímico e bioensaio toxicológico frente a larvas de Artemia salina Leach. de três espécies medicinais do gênero Phyllanthus (Phyllanthaceae).

Revista Ciências Farmacêuticas Básica e Aplicada, Araraquara, v.29, n.2, p.143-148, 2008.

OLIVEIRA, D.F. et al. "Antibacterial activity of plant extracts from Brazilian southeast region" Fitoterapia, v.78, p.142-145, 2007.

OPLUSTIL, C.P. et al. Procedimentos básicos em microbiologia clínica. São Paulo: Sarvier, 2000.

PADILHA, I.Q.M. et al. Antimicrobial activity of Mimosa tenuiflora (Willd.) Poir. From Northeast Brazil against clinical isolates of Staphylococcus aureus. Revista Brasileira de Farmacognosia, São Paulo, v.20 n.1, p.4547, Jan./Mar. 2010.

PAREKH, J. e CHANDA, S.V. In vitro antimicrobial activity and phytochemical analysis of some Indian medicinal plants. Turkish Journal of Biology, v.31, p.53-58, 2007. RIBEIRO, C.M. Avaliação da atividade antimicrobiana de plantas utilizadas na Medicina popular da Amazônia2008. 66p. Dissertação (Mestrado) - Programa de PósGraduação em Ciências Farmacêuticas. Instituto de Ciências da Saúde. Universidade Federal do Pará, Belém. RIBEIRO, M.C. e SOARES, M.M.S.R. Microbiologia prática: roteiro e manual. São Paulo: Atheneu, 2000.

SANTOS, S.C. et al. Atividade antimicrobiana in vitro do extrato de Abarema cochiliocarpos (Gomes) Barnaby \& Grimes. Revista Brasileira de Farmacognosia, São Paulo, v.17, n.2, p.215-219. 2007.

SARTORI, M.R.K. Atividade antimicrobiana de fração de compostos puros obtidos das flores da Acmela brasiliensis Spreng (Wedelia paludosa) (Asteraceae). 2005, 81p. Dissertação (Mestrado) Ciências Farmacêuticas. Universidade do Vale do Itajai, Santa Catarina.

SILVA, J.G. et al. Atividade inibitória das folhas e caule de Kalanchoe brasiliensis Cambess frente a microrganismos com diferentes perfis de resistência a antibióticos. Revista Brasileira de Farmacognosia, São Paulo, v.19, n.3, p.790-794, jul./set. 2009.

SILVEIRA, L.M.S. et al. Metodologias de atividade antimicrobiana aplicadas a extratos de plantas: comparação entre duas técnicas de ágar difusão. Revista Brasileira de Farmácia, Rio de Janeiro, v.90, n.2, p.124-128, 2009.

SIMÕES, C.M.O. et al. Farmacognosia: da planta ao medicamento. 5. Ed. Porto Alegre/Florianópolis: Editora da UFSC, 2004. 1102p.

TORTORA, G.J.; FUNKE, B.R.; CASE, C.L. Microbiologia. 8. Ed. Porto Alegre: Ed. Artmed, 2005. 894p.

VIDAL O. et al. Isolation of an Escherichia coli K12 Mutant Strain Able To Form Biofilms on Inert Surfaces: Involvement of a New ompR Allele That Increases Curli Expression. Articles from Journal of Bacteriology are provided here courtesy of American Society for Microbiology (ASM), Washington, 1998.

Rev. Bras. PI. Med., Botucatu, v.15, n.1, p.104-111, 2013. 